УДК 821.161.1-346.4.09:316.3

\title{
СОЦИАЛЬНОЕ ПРЕДНАЗНАЧЕНИЕ РУССКОЙ СКАЗКИ
}

\author{
Суслов Андрей Александрович, \\ as8282@list.ru \\ Орлова Вера Вениаминовна, \\ orlova_vv@mail.ru \\ ${ }^{1}$ Томский механико-технологический техникум, \\ Россия, 634050, г. Томск, ул. К. Ильмера, 4. \\ 2 Томский государственный университет систем управления и радиоэлектроники, \\ Россия, 634050, г. Томск, пр. Ленина, 40.
}

Суслов Андрей Александрович, преподаватель специальных дисциплин Томского механикотехнологического техникума.

Орлова Вера Вениаминовна, доктор социологических наук, профессор кафедры философии и социологии Томского государственного университета систем управления и радиоэлектроники.

Актуальность исследования определяется онтологической вариативностью, различием способов познания, что представляет разные картины мира. Данная мозаика миропонимания обуславливает проблему обретения целостности как системы единого неразделенного знания. Механизм дополненной реальности, перцептуального и концептуального видов пространства-времени в сказках представляет наибольший исследовательский интерес и эвристический потенциал. Субъективное восприятие мира в пространстве-времени может быть осознано посредством способов моделирования географической, хронологической составляющих, характерных для концептуального пространства-времени. Целью исследования является актуализация целостности (формы родственности) генезиса социальных норм в архачческих формах синкретического мышления (русских сказках). В статье ставится задача рассмотреть идею родства как формы социального предназначения русской сказки. Методы. Авторы опирались на абстрактно-логический, феноменологический подходы, методы анализа, синтеза, типологизации. Результаты. В контексте воплощения идеи родства социальное предназначение русских сказок вариативно. Смысл сказок раскрывается различными способами: целостностью - синтезом образно-символической архаической природы сознания в художественном пространстве-времени сказки; созданием поэтических форм в контексте единства перцептуального, концептуального и реального пространства-времени. С точки зрения семантики пространства-времени социальное предназначение определено императивами, универсалиями знакового (символьного) осмысления мира посредством трактовки сказки как системы символов. Социальные постулаты архаики воплощены в коллективных образах единого, целого, являют результат воплощенной в сказках гармонии внутреннего и внешнего миров (реального и субстанционального).

Ключевые слова: Сказка, пространство-время, социальное предназначение, дополненная реальность, универсальность.

В настоящее время существует множество способов познания мира: научный, религиозный, мифологический, философский, познание средствами искусства. Онтологическая вариативность, обусловленная различием способов познания, представляет соответственно вариативные картины мира. Господствующее в архаике мифологическое сознание основывалось на синкретической (неразделенной) системе миропонимания, 
взаимодействия всех элементов. Миры людей, природы были как противопоставлены, так и одновременно едины, неделимы. Религиозный способ миропонимания основывается на перцептивном осознании самости посредством веры в Бога и постулаты Святого писания. Эмпирическое знание, обладающее собственным методологическим аппаратом, демонстрирует аутентичную картину мира. Разность способов миропонимания и одновременно различные достигаемые результаты, получаемые в предметном поле наук, философии, религии, различных видах искусства обуславливают проблему обретения целостности как системы единого неразделенного знания. С целью актуализации целостности (формы родственности) генезиса социальных норм целесообразно обратиться к архаическим формам синкретического мышления (русским сказкам).

Искусству как форме выражения сущности человека свойственны аутентичные способы выражения пространства и времени. Одним из признаков, отличающих искусство от иных видов деятельности человека, является особая связь перцептуального, концептуального и реального пространства-времени. Б. Рассел впервые разграничил перцептуальное и реальное пространство-время. Основой данного разделения послужили психофизиологические особенности восприятия мира посредством органов чувств, рефлексии получаемой информации. Перцептуальное в отличие от реального пространствавремени в искусстве носит субъективный характер, способом объективации перцептуального пространства-времени является художественный образ, «представляющий собой основное содержание всякого произведения искусства, может быть реализован только в рамках перцептуального пространства и времени субъекта, создающего или воспринимающего художественное произведение» [1, с. 15]. Реальное пространство-время отображает свойства объектов, вещей в виде материи, физических свойств. Концептуальное пространство-время представлено в виде модели происходящих явлений, ситуаций, что позволяет выстроить событийную, хронологическую логику. Искусство, реализуемое посредством художественного образа, представлено в трех видах пространства-времени: реальном, концептуальном и перцептуальном. Наибольший интерес представляет механизм дополненности рассматриваемых видов пространства-времени. Интуитивное, субъективное восприятие мира (перцептуальное пространство-время) не может быть осознано в полной мере без способов моделирования географической, хронологической составляющих, характерных для концептуального пространства-времени. Механизм дополненности перцептуального и реального пространства-времени присутствует в русских сказках. Герои сказок то погружены в определенное пространство-время с выраженными географическими, событийными и временными характеристиками, то, напротив, отдалены от всякого рода пространственно-временной конкретики. Смена шкалы координат (перцептуальное - реальное, реальное - перцептуальное пространство-время) сравнима с переходами между мирами: земной-небесный - подземный. Способом такого «перехода» являются возможности художественного образа. Субъективное психофизиологическое восприятие мира посредством художественного образа иррационально и рационально одновременно. Гносеологический аспект роли художественного образа в детерминированном пространстве-времени состоит в том, что в различных видах искусства, в том числе и сказках, процесс отражения реального пространства-времени в перцептуальном рождает образ художественного пространства и художественного времени. Наслоение художественных образов и художественных образов пространства-времени представляет систему взаимозависимости, целостной картины описываемого и реального миров. Организующая роль художественного образа в сказках в контексте целостности реальногоконцептуального-перцептуального пространства-времени принадлежит воплощению 
идеи родства как инструментария познания художественного мира и расширения знаний о реальности посредством глубокой рефлексии перцептуального пространства-времени.

В современной массовой культуре широко транслируемыми образами являются сказочные персонажи, фильмы, аниме, реклама, которые изобилуют яркими и понятными персонажами. Медийный образ зачастую не имеет ничего общего с тем, который представлен изначально в сказках. Отрицательные и положительные герои сказок продукт воображения и толкования сказок в угоду яркого сюжета, характеризующего острую социальную значимость [2]. В буквальном толковании сказка является определенным текстом, понимание которого зависит от множества характеристик (стереотипность, гендерность, политичность), что отмечено учеными В.Ф. Петренко [3], А.Е. Наговицыным [4], занимающимися анализом восприятия ритмо-фонетической структуры текста. В.Ф. Петренко, указывая на фактор отражения действительности в тексте, отметил: «Действительность представлена субъекту не только через чувственную модель, но и через знаковые, концептуальные модели, вернее в их единстве» [3, с. 56]. Развивая идею единства концептуального, знакового, чувственного способов познания мира, А.Е. Наговицын определил, что обобщение, анализ информации таким образом ведут к созданию категориальной структуры сознания, имеющей для субъекта собственный онтологический статус и образующей многовариантное семантическое пространство [3]. Синтез архаических, мифологических, социальных и иных представлений в рамках семантического пространства русской сказки являет вариативность трактовки сюжетов сказки в зависимости от рассматриваемого критерия. Таким образом, один и тот же сюжет русской сказки можно рассматривать как с позиции анализа архаических символов, сознания, так и с точки зрения генезиса, например социальных, политических институтов (семьи, государства, власти).

Поэтическая форма, художественность русской сказки в прямом и буквальном толковании иррациональны, обременены излишними словесными повторами, украшательствами слов, вызывающих различные ассоциации, и, таким образом, формируются различия толкования отдельных сюжетов у слушателей сказок. Рассматривая русскую сказку как древнейший вид творческой деятельности, ученые (М.M. Бахтин, В.Я. Пропп) отмечали, что в ней заложены идеи архаических представлений о мире, являющихся формой философичности мыслей людей до появления русской философии. Сказка, таким образом, была не только поэтическим текстом, но и стала первой ступенью зарождения общего знания.

Вариативность трактовок сюжетов, используемых символов в сказке не умаляет априори присущую ей единообразную логику осмысления и обдумывания. Из чего мы заключаем, что единая логика трактовки семантического пространства сказки дополнена единым способом упорядоченной рефлексии. Ограниченность внешней символьной среды (символы, знаки, звуки, цвета) с успехом компенсировались упорядоченным «языком общения мыслями». Возможно, именно по этой причине первые способы отражения и фиксации информации выражались мыслями, категориями, образами. Сопоставление мыслей, фонетической структуры слова, визуального ряда (написания) привели к утрате единого логического механизма смыслового языка. Немецкий философ Г.В. Лейбниц пришел к выводу о несостоятельности современного языка по причине знаковой, содержательной ограниченности, выход из проблемы предлагал искать в создании системы «всеобщего языка», доступного и понятного каждому. Такой язык (пазиография), по мнению ученого, должен был по максимуму содержать изобразительные средства, представленные в виде универсальных понятий о предмете, и формировать тем самым некую логико-эмпирическую систему или «алфавит человеческих 
мыслей» $[4$, с. 112]. Теорию всеобщего языка Г.В. Лейбниц обосновал, опираясь на материалы древних языков, пиктографии, иероглифического письма.

Таким образом, если рассматривать сказку как текст (набор письменных знаков, символов), то буквальное толкование не может дать верный результат и не позволит приблизиться к пониманию изначального смысла, используемой символики, художественных образов. Будучи артефактом дописьменной культуры сказка представляла собой синтез логического смыслового обобщения о происходящих явлениях, событиях, объектах, формируя универсальные способы хранения, передачи информации, позволяющие воспринимать мир как целый живой организм. Полагаем, что универсальность семантического пространства сказки, сравнимой с всеобщим языком Г.В. Лейбница, заключается в целостности, однородности используемых мифологических символов, объектов и изначальной архаической синкретической логики. Сказка как артефакт архаической культуры вобрала в себя древние представления о целостной структуре мира, трансформируемой в плоскость социальной модели общества в зависимости от его уровней («Верхнего», «Земного», «Нижнего»). Сказка предвосхищала популяризацию различных жанров искусства и культуры, трансцендентальность в социальном контексте сказки заключается репрезентации арахаики, традиций, ритуалов в виде магических символов, персонажей [5].

Румынский исследователь славянского фольклора Мирча Элиаде полагал, что символы, используемые в мифах, сказках носят религиозный характер, поскольку сам процесс создания мира, человека, живых существ в архаическом сознании являл божественный промысел. Выяснение смысла, трактовка сюжета сказки невозможны без учета наличия в архаическом сознании устойчивой органической связи человека и познаваемого объекта, обладающего экзистенциональной потенцией. Эта связь сопоставима с приоткрытием, приобщением к божественному (недоступному в полной мере для человека) знанию.

Погружение в художественное пространство сказки, следуя логике М. Элиаде, ситуативно. Раскрытие архаической символики сопряжено осознанием внутренней упорядоченности, единства космических структур (устройство мира) и духовного опыта человека. М. Элиаде считал, что большинство религиозных символов посвящено целостности, единству мира. Смысловая вариативность символики заключается в обобщении символов, их взаимозависимости, и этот процесс формирует единую смысловую целостность [6]. Ученый указывал, что одной из функций религиозной символики является отображение парадоксальной ситуации. В сказках, следуя логике М. Элиаде, причудливое описание героев, событий вызывает яркие ассоциации и четкое понимание происходящего, несмотря на фантазийность, нелогичность происходящего. Парадоксальные ситуации играют роль перехода между мирами, фиксации ритуальных действий, табуирования. Целостность, взаимозависимость, вариативность символической среды сказки представлены в форме родственности реального и экзистенционального миров, границей (переходами) между мирами служат нетипичные (пародоксальные) ситуации. А.Ф. Лосев в подтверждение идеи всеобщности как целостной органической системы отмечал: «...природа, общество, мир - царство символов. Целостность мира обеспечивается благодаря взаимосвязи всех вещей и осознания самости какого-либо объекта посредством выявления связей с другими объектами и вещами [4, с. 206]. Согласно М. Элиаде, процесс осознания мира посредством символа тождественен приобщению индивида с его сиюминутными потребностями к общему (вечному), и, таким образом, индивидуальное возводится в ранг системы всеобщего (божественного, космического) [6, с. 185]. 
В сказках частное становится общим повсеместно. Как правило, герои, решая собственные семейные дела (поиск супруги, брата, сестры), сталкиваются одновременно с ситуациями объективного характера (силы природы в виде мифических персонажей Змея Горыныча, Кощея Бессмертного, Бабы Яги). Ритуализированность сакральных действий и одновременная сопричастность к мирским делам как формы семейственности, социальной значимости ярко проявлены в персонаже Бабы Яги. Восточный образ дикой ведьмы в зарубежных изданиях воплощен как уникальный, в большей мере созидающий персонаж, хранитель древних знаний [7]. Успешное разрешение ситуативной задачи в рамках заданного сюжета свидетельствует о преодолении разноплановых трудностей (испытание героя), которые ограничивают, погружают уже лиц, слушающих сказку, в недоступный мир сакрального знания. Символы архаического космоса, транслируемые в сказке, содержат идею гармонии мира, сопричастности его структур, субъектов, объектов. Первичным элементом данной системы выступает символ, который выполняет как частную, так и обобщенную функции. Как отмечал Г.-Г. Гадамер: «Познание символического смысла предполагает, что единичное, особенное представляет как осколок бытия, способный соединиться с соответствующим ему осколком в гармоничное целое, или же что это - давно ожидаемая частица, дополняющая до целого наш фрагмент жизни» [4, с. 175].

О необходимости выстраивания единства форм (буквальной, фонетической и смысловой) языка писал Л.С. Выготский. Слово, согласно ученому, вобрало резюмирующие итоги психологического, смыслового и иных форм обобщения. Таким образом, слово само по себе отражает действительность иначе, чем в ощущениях и восприятиях: «... всякое слово уже обобщает с психологической точки зрения значение слова, прежде всего представляет собой обобщение. Но обобщение, как легко видеть, есть чрезвычайный словесный акт мысли, отражающий действительность иначе, чем она отражена в непосредственных ощущениях и восприятиях» [8, с. 154]. Известно, что сказка как форма устного народного творчества существует в культурных традициях многих народов мира. Традиции сюжетно, идейно связаны между собой. Сказки, таким образом, выполняют интернациональную роль сближения народов. Как отмечал В.Я. Пропп: «Замечательно не только широкое распространение сказок, но и то, что сказки народов связаны между собой. До некоторой степени сказка - символ единства мира» [9, с. 25].

Социальное предназначение русской сказки в нашем понимании транслирует собирательные образы в контексте коллективного начала - идеи родства, воплощенной в общей концептуальной схожести (родственности) идейной, сюжетной, символикообрядовой, ритуальной форм культуры народов. Безусловно, речь в данном случае не может идти об абсолютной тождественности всех мифов, сказок народов мира. Схожесть, равно как и культурная родственность сюжетов сказок, основана прежде всего на едином подходе миропонимания посредством трактовки мифологической символики и восприятия в пространственно-временном контексте. А.Е. Наговицын полагает, что символы (в том числе символы в сказках) сами по себе изолированно не воспринимаются сознанием. Следовательно, смысловое структурирование как часть процесса осознания символа возможно в условиях нахождения (погружения) в конкретное пространство-время: «В устном или письменном повествовании (например, в сказке, легенде и т. д.) символы разворачиваются, хронологически сгущаясь в пространстве...» [4, с. 280]. Выясняя сущность символа на основе изучения мифов, сказок, А.Е. Наговицын отметил, что символы по своей природе обладают побудительным механизмом воздействия на различные социальные, культурные и психические формы деятельности человека, общества, используют разные виды воздействия как на отдельного человека, так и на 
общество в целом. По этой причине «сгущение» символа в пространстве-времени приводит к различным трактовкам. Символ распадается на «матрицу символов», охватывающую все виды социально-культурного и социально-психологического пространства-времени человека и человечества в целом [4]. Бытие символа в художественном пространстве-времени, согласно А.Е. Наговицыну, обладает признаками целостности, проявлено в единстве целей (целенаправленно), имеет единые свойства (эмерджментно) и обладает единонаправленностью (синергично) [4].

Нерасчлененность познаваемой картины мира посредством априори свойственного сказке архаического синкретизма формировало образность, идейную созависимость всех явлений, объектов природы. Р. Штайнер, исследуя с научных позиций произведения И.В. Гете, отмечал организующую роль упорядоченного мышления посредством сказочных образов. Физический мир, познаваемый органами чувств и исследуемый современной наукой противопоставлен трансцендентальному (сверхчувственному) миру. В «Сказке» И.В. Гете показаны оба этих мира: реальный (осязаемый) и познаваемый (за гранью реальности, открываемый). Несмотря на антогонизм, Р. Штайнер считал, что связующим элементом описываемых миров является сказочный образ. Например, в «Сказке» образ открытия, познания нового воплощен в виде человека в темноте с лампой в руках, образ змея характеризует способ восприятия мира, осязанием (первичностью чувственной перцепции). Противопоставленность миров по И.В. Гете заявлена не как средство демонстрации имеющихся противоречий, несогласованности, а соответствует идее сближения, единения (кратковременного и функционального) чувственного и сверхчувственного миров с целью достижения истины: «Ибо даже если кто-то возразит, что под «воздействием сил» имеются в виду силы разных людей, все же справедлива и та очевидная для Гете истина, что силы души, порознь распределенные по отдельным людям, суть не что иное, как разъятая на части сущность одного целостного характера» [8, c. 171].

Таким образом, объединительная природа сказки выражена в присутствующих в мышлении человека компонентах сознания, которые характеризуются осознанием своей сущности путем сближения чувственной (физической) и трансцендентальной природой. Такого рода сближение разноипостнастных миров и, соответственно, уровней сознания демонстрирует сказка путем аккумуляции архетипов, то есть зафиксированных древних образов, формирующих и моделирующих поведение людей. Архетипы складывались стихийно, органично воздействовали на общество, устанавливали и определяли социокультурные нормы и установки [9]. Архетипические образы, символы как элементы психологии бессознательного наиболее ярко выражены в мифах, сказках, обрядах, ритуалах. А.Е. Наговицын, рассуждая об архетипической природе мифа в контексте связи со сказкой, отметил: «Миф - не символ, но он, безусловно, символичен, и нам представляется справедливой мысль А.Ф. Лосева о том, что он (миф) несет в себе общую идею в виде живого существа, а живое существо бесконечно по своим возможностям» [4, с. 265].

К.А. Свасьян обратил внимание на символическую природу мифов и сказок, отметил, что многие сказочные образы, аллегории обладают «единособирательностью». Эти свойства, по мысли ученого, определяют процесс «мифического действа», помогают расставить акценты, развивать сюжет [4, с. 232]. Дополняя точку зрения К.А. Свасьяна, А.Е. Наговицын отметил, что миф - «система символов», обусловленная социомифологической средой. Слагаемые миф элементы обладают как целостностью, так и делимостью.

Понимание мифа (сказки), на наш взгляд, связано тем самым с конкретной системой символов в определенных социокультурных, исторических условиях. В связи с чем 
распространенным явлением могут быть дублирование, вариативность трактовок как самих символов, так и в целом системы символов (сказок). Единособирательность как признак воплощенной в сказке идеи родства вариативна в зависимости от заданных условий социокультурной среды. Диалектичность символа в мифах, сказках построена на логике противопоставленного, противоречивого. Единство бинарных оппозиций («свой-чужой», «земной-небесный») обусловлено созависимостью и одновременно содержательной наполненностью разнополярных миров. Наиболее ярко соприкосновение, пересечение разноипостнастных миров представлено в ритуалах, празднествах. Миросоздающая и взаимодополняющая функция противопоставленных образов, явлений наличествует в архаическом сознании в контексте духовной стихии, психоэмоциональных переживаниях.

К. Леви-Стросс, рассматривая основания системы родства как соответствие внешних форм поведения человека и смыслового содержания символа, полагал, что в символической системе присутствует «индуктивная способность», которой обладают схожие элементы, организующие физические и психические процессы. Формой проявления описываемой «индукции» служит поэтическая метафора, являющаяся непременным атрибутом сказок. Бессознательное, согласно выводам К. Леви-Стросса, заключает в себе единство форм проявлений эмоций, переживаний, законов функционирования рефлексивной логики, образующейся в результате психоэмоционального переживания у людей [10]. Проблема интерпретации, осмысления артефактов ранних культур связана, по мнению ученого, с утратой способов (кодов) устойчивой связи символов в современных культурах («горячих культурах») в связи с их активным развитием, приобщением к новому. «Холодные культуры», напротив, демонстрируют наличие связи в сказках, мифах, ритуалах, масках [10]. Сохранению устойчивых связей символов в мифах, сказках возможно благодаря ритуалу. Ритуализированность действий, образов; цветовая архаическая семантика обеспечивают конституирование смыслового поля символической системы мифа (сказки). Одним из признаков ритуала является повторение действий, слов, жестов. С. Кьеркегор, изучая природу экзистенциального сознания, утверждал, что мотивом «повторения» является достижение целостности, гармонии идеального с реальным [4].

Ритуализированность как фактор программируемости, осмысленности и одновременно хаоса наглядно демонстрирует карнавальная культура. М.М. Бахтин, исследуя карнавал и смеховую культуру разных народов, отмечал, что существует язык толпы, карнавала, свободный от официальных норм и правил. Этот язык объединяет, роднит все другие формы жизни в единое и показывает «жизнь наизнанку». М.М. Бахтин пришел к выводу, что народный язык складывался под воздействием карнавальной культуры [11].

А.А. Гагаев в монографии «Русская цивилизация и фольклор. Мир русской сказки» рассмотрел сказку как многогранное явление культуры (связь русской сказки с политикой, социумом, культурой, философией, психологией) и отметил, что карнавал, праздник «есть подлинная форма жизни (ее эстетика)» [12, с. 81]. Карнавальная трактовка идеи родства выражена, на наш взгляд, в скреплении базовых смыслов, элементов и одновременно в сближении реального и экзистенциального миров. Русская сказка как форма репрезентации архетипической коллективной сущности являет ценность семьи и воплощения семейности как основы идеи родства. Изображаемый мир в сказках априори знаком, герои связаны как прямыми, так и косвенными родственными связями. Центральным сюжетом сказок, как правило, являются поиски жены, сестры, брата, матери. Обретение (воссоединение) с семьей достигается благодаря усилиям и испытани- 
ем героев (проход в разные миры, например, в тридевятое царство за тридевять земель, сражение с Кощеем Бессмертным, Змеем Горынычем).

Исследователь румынских сказок Николае Рошияну рассмотрел традиционные формулы (словесные, смысловые), выделил аналогии и различия, встречающиеся в текстах румынских, сербских, албанских, русских и других сказок славянских народов. Ученый отдельно выделил элементы формул, характеризующих семейность. Экосистемность, единособирательность в русских сказках проявлены в формах социальной интерпретации действий людей, воплощены в образах животных [13].

Например, одной из подобных словесных формул является «хлеб-соль». Н. Рошияну отметил, что «хлеб-соль» символизирует у многих народов гостеприимство, благожелательную встречу гостей или даже чужих людей. В некоторых случаях эта фраза играет роль приветствия: «Хлеб-соль, добрый молодец» [13].

В сказках идея родства часто выражена в образе сказочного царя. Царь и члены его семьи (царица, царевич) образуют модель семьи. Сказочный царь не отстранен и не отгорожен от своих подданных, самые сложные поручения царя выполняет крестьянский сын Иван-дурак. Власть царя органична и не является чуждым явлением.

Дж.Дж. Фрэзер, описывая роль царя, отметил: «Царь является точкой опоры, поддерживающей равновесие мира: малейшая неточность с его стороны может это равновесие нарушить» [14, с. 185]. Благоденствие как равновесие связывалось с обликом стабильной власти, отождествляемой в сказках с наличием правителя (царя). Тем самым в сказках роль царя заключается не только в осуществлении государственного управления, но и в достижении согласованности, социального и духовного равновесия, интерпретируемого нами, как воплощение идеи родства мира природы и людей. В образе сказочного царя проявлены архетипические идеи единства миров (царь священен, сакрален), общение с царем равнозначно погружению в иной мир. С другой стороны, открытость царя (в сказках часто присутствуют описание быта царей), характеризует его как члена большой семьи.

Родство в сказках также может быть выражено как культурное единство, имеющее географические и национальные ареалы. Русские сказки изобилуют тематикой освоения географического пространства: «Сказка внесла свой вклад в развитие геополитического мышления русского человека. Сказка в веках поддерживала своего слушателя в том, что везде он - у себя дома (нигде не теряется)» [11, с. 140]. Странствия героев сказок сопровождаются освоением как («своего») реального, так и («чужого») субстансциального миров. Пройдя через поля, леса, болота, герои попадают на периферию миров (реального и субстанционального), представленную, например, в образах Бабы Яги, горы, моря. Попав в «иной мир», как правило, герои умело в нем ориентируются и с той же легкостью его покидают, либо преобразуют до состояния «родных мест».

В способах освоения различных миров и траектории странствий героев русских сказок заключена идея срединности, единособирательной индукции осмысления мира посредством чувственного и сверхчувственного опыта: «Срединность (планетарность) духовности человека выражается и в готовности его встать на уровень с бытием, сразиться с инобытийными реалиями и победить. Без этого нет человека как воссобирающего все и вся в единое светлое соборное целое» [12, с. 146]. С другой стороны, учитывая архаическую природу бинарных оппозиций, сказка демонстрирует сущность каждого из миров, сувереном которых выступают смысловые, логические координаты, позволяющие героям ориентироваться в данных мирах (во всех мирах свой царь, свое государство, свое пространство-время, отличные от всех иных). А.А. Гагаев указал на целостность русской сказки в ее одновременно демонстрируемой разности миров, отме- 
тил, что фактором, «скрепляющим» разноипостастные миры является мотив добра и обретения счастья.

На наш взгляд, логическая целостность разнополярных миров в сказках достигается не только побуждением к нравственному подвигу (добру), а также в результате мотивированного дисбаланса внутренней гармонии, утраты целостности (как явления «недостачи» у В.Я. Проппа) и, соответственно, редуцированного желания обретения «утраченного» с целью самопознания (поиска самости) [15, с. 57]. Социальный колорит в сказках представлен в образах животных, олицетворяющих действия, мысли и поступки героев [16].

Таким образом, социальное предназначение русских сказок в контексте воплощения идеи родства вариативно, может быть выражено различными способами. Достижение целостности в художественном пространстве-времени сказки представляет синтез образно-символической архаической природы сознания; поэтических форм в контексте единства перцептуального, концептуального и реального пространства-времени. В семантическом пространстве-времени социальное предназначение определено как императивами, так и универсалиями знакового (символьного) осмысления мира посредством трактовки сказки как системы символов. В геополитическом, географическом фокусах пространства-времени социальное предназначение русских сказок воплощено в интернациональной функции общности символов, знаков, атрибутов архаической культуры народов. Социальные постулаты архаики воплощены в коллективных образах единого, целого, являют результат воплощенной в сказках гармонии внутреннего, внешнего миров (реального и субстанционального).

\section{СПИСОК ЛИТЕРАТУРЫ}

1. Зобов Р.А., Мостапенко А.М. О типологии пространственно-временных отношений в сфере искусства // Ритм, пространство и время в литературе и искусстве; отв. ред. Б.Ф. Егоров. - Ленинград: Наука (Ленинградское отделение), 1974. - С. 11-25.

2. Rudy J.T., McDonald J.L. Baba Yaga, Monsters of the Week, and Pop Culture's Formation of Wonder and Families through Monstrosity // Humanities. - 2016. - № 5 (2). - V. 40. URL: https://www.mdpi.com/20760787/5/2/40 (дата обращения 03.05.2019).

3. Петренко В.Ф. Психосемантика сознания. - М.: Изд-во МГУ, 1988. - 207 с.

4. Наговицын А.Е., Пономарева В.И. Симвология: от философских теорий до практики сказкотерапии М.: Генезис, 2014. - 302 c.

5. Savannah Blitch. Between Earth and Sky: Transcendence, Reality, and the Fairy Tale in Pan's Labyrinth // Humanities. - 2016. - № 5 (2). - V. 33. URL: https://www.mdpi.com/2076-0787/5/2/33 (дата обращения 03.05.2019).

6. Элиаде М. Тайные общества. Обряды, инициации, посвящения. - СПб.: Университетская книга, 1999. - 340 c.

7. Hutctherson C.Th. Baba Yaga: Wild Witch of the East in Russian Fairy tales / Ed. by S. Forrester, M. Skoro, H. Croscilo. - Paris: Marvels \& Tails Publю, 2016. - 202 p.

8. Гете И.В. Тайны. Сказка. - М.: Энигма, 1996. - 248 с.

9. Юнг К.Г. Об архетипах коллективного бессознательного // Вопросы философии. - 1988. - № 1. С. $45-68$.

10. Леви-Стросс К. Структурная антропология. - М.: АСТ: Астрель, 2011. - 544 с.

11. Бахтин М.М. Эстетика словесного творчества. - М.: Наука, 1979. - 236 с.

12. Гагаев А.А., Гагаев П.А. Русская цивилизация и фольклор. Мир сказки - М.: РИОР, 2014. - 200 с.

13. Рошияну Н.У. Традиционные формулы сказки. - М.: Наука, 1974. - 216 с.

14. Фрезер Д.Д. Золотая ветвь. - М.: АСТ-Москва, 2009. - 767 с.

15. Пропп В.Я. Морфология сказки. - М.: Наука, 1969. - 122 с.

16. Kadyrbekova Z. Animals agents in Russian fairy tales // Canadian Slavonic Papers. - 2018. - V. 60. Iss. 3-4. - P. 1-19.

Поступила 12.06.2019 г. 
UDC 821.161.1-346.4.09:316.3

\title{
SOCIAL PURPOSE OF RUSSIAN FAIRY TALES
}

\author{
Andrey A. Suslov, \\ as8282@list.ru \\ Vera V. Orlova, \\ orlova_vv@mail.ru \\ ${ }^{1}$ Tomsk mechanics and Technology College, \\ 4, K. Ilmer street, Tomsk, 634050, Russia. \\ 2 Tomsk State University of Control Systems and Radioelectronics, \\ 40, Lenin Avenue, Tomsk, 634050, Russia.
}

Andrey A. Suslov, teacher of special disciplines, Tomsk mechanics and Technology College.

Vera V. Orlova, Dr. Sc., professor, Tomsk State University of Control Systems and Radioelectronics.

Relevance of the research is determined by the ontological variability, difference of cognition methods that represents the variation pattern of the world. The mosaic philosophy causes the problem of independence of integrity as a single knowledge left unpartitioned. The mechanism of augmented reality perceptual and conceptual types of space-time in fairy tales is the largest research interest and heuristic potential. Subjective perception of the world in space-time can be realized by the way of simulating geographic, chronological components, characteristic of concept of space-time. The aim of the study is to update the integrity (affinity) of genesis of social norms in the archaic forms of syncretic thinking (Russian fairy tales). The article seeks to address the idea of kinship as a form of social purpose of Russian fairy tales. Methods. The author relied on abstract-logical, phenomenological approaches, a wide range of sources of socio-philosophical content. The results. In the context of the kinship concepts the social purpose of Russian fairy tales vary. It can be expressed in different ways: integrity - synthesis of figurative-symbolic archaic nature of consciousness in the tales art space-time; creation of poetic forms in the context of the unity of perceptual, conceptual and real space-time. In terms of space-time semantics the social purpose is defined by imperatives, universals of signed (character) reflection of the world through interpretation of fairy tale as a system of symbols. Social tenets of archaic art are embodied in the collective images of a single, whole, represent the result of domestic harmony, external worlds (real and substantial) embodied in the tales.

Key words: Fairy tale, space-time, social purpose, augmented reality, universality.

\section{REFERENCES}

1. Zobov R.A., Mostapenko A.M. O tipologii prostranstvenno-vremennykh otnosheniy v sfere iskusstva [On the typology of space-temporal relations in the field of art]. Ritm, prostranstvo $i$ vremya $v$ literature $i$ iskusstve [Rhythm, space and time in literature and art]. Ed. by B.F. Egorov. Leningrad, Nauka (Leningradskoe otdelenie) Publ., 1974. 298 p.

2. Rudy J.T., McDonald J.L. Baba Yaga, Monsters of the Week, and Pop Culture's Formation of Wonder and Families through Monstrosity. Humanities, 2016, no. 5 (2), vol. 40 . Available at: https://www.mdpi.com/2076-0787/5/2/40 (accessed 3 May 2019).

3. Petrenko V.F. Psikhosemantika soznaniya [Psychosematics of consciousness]. Moscow, Moscow University Publ., 1988. 207 p.

4. Nagovitsyn A.E., Ponomareva V.I. Simvologiya: ot filosofskikh teoriy do praktiki skazkoterapii [Symbology: from philosophical theories to the practice of fairy tales]. Moscow, Genezis Publ., 2014, 302 p.

5. Savannah Blitch. Between Earth and Sky: Transcendence, Reality, and the Fairy Tale in Pan's Labyrinth. Humanities, 2016, no. 5 (2), vol. 33. Available at: https://www.mdpi.com/2076-0787/5/2/33 (accessed 3 May 2019). 
6. Eliade M. Taynye obshchestva. Obryady, initsiatsii, posvyashcheniya [Secret societies. Rites, initiations, initiations]. St-Petersburg, Universitetskaya kniga Publ., 1999. 340 p.

7. Hutctherson C.Th. Baba Yaga: Wild Witch of the East in Russian Fairy tales. Eds. S. Forrester, M. Skoro, H. Croscilo. Paris, Marvels \& Tails, Publ., 2016. 202 p.

8. Gete I.V. Tayny. Skazka [Mysteries Tale]. Moscow, Enigma Publ., 1996. 248 p.

9. Yung K.G. Ob arkhetipakh kollektivnogo bessoznatelnogo [On the archetypes of the collective unconscious]. Voprosy filosofii, 1988, no. 1, pp. 45-68.

10. Levi-Stross K. Strukturnaya antropologiya [Structural anthropology]. Moscow, AST, Astrel Publ., 2011. $544 \mathrm{p}$.

11. Bakhtin M.M. Estetika slovesnogo tvorchestva [Aesthetics of verbal creativity]. Mocow, Nauka Publ., 1979. $236 \mathrm{p}$.

12. Gagaev A.A., Gagaev P.A. Russkaya tsivilizatsiya i folklor. Mir skazki [Russian civilization and folklore. Fairy tale world]. Moscow, RIOR Publ., 2014. 200 p.

13. Roshiyanu N.U. Traditsionnye formuly skazki [Traditional fairy tale formulas]. Moscow, Nauka Publ., 1974. $216 \mathrm{p}$.

14. Frezer D.D. Zolotaya vetv [Golden branch]. Moscow, AST-Moskva Publ., 2009. 767 p.

15. Propp V.Ya. Morfologiya skazki [Morphology of a fairy tale]. Moscow, Nauka Publ., 1969. 122 p.

16. Kadyrbekova Z. Animals agents in Russian fairy tales. Canadian Slavonic Papers, 2018, vol. 60, Iss. 3-4, pp. 1-19.

Received: 12 June 2019. 